\title{
1992 Trainees' Forum: Psychiatry in the Europe of the 1990s
}

\author{
Michael van Beinum and David Castle, Collegiate Trainees' Committee
}

On 21 January 1992 the annual Trainees' Forum, organised by the Collegiate Trainees' Committee, was held in London as part of the Winter Quarterly Meeting of the Royal College of Psychiatrists. The theme was European integration and the implications for training in psychiatry. Three speakers presented different aspects of this topic: Dr Fiona Caldicott, Dean of the Royal College of Psychiatrists, spoke on the role of the College in Europe; Dr Sharon Binyon, of the BMA Permanent Working Group of European Junior Doctors, spoke on medical manpower issues; and Dr Jim van Os, from the Institute of Psychiatry, looked at recent research illustrating differences in the understanding and treatment of psychiatric illnesses between France and the UK.

Medical manpower has been of concern in the planning of training posts, as many European countries, such as Italy and Spain, have for many years overproduced doctors (see Brearley, 1991). This has led to both unemployment and underemployment of doctors. In addition, in some European countries it has been very difficult to obtain higher training in some specialities, forcing doctors to work for no pay in order to get onto specialist training schemes. Since many European doctors are fluent in English, the fear has been expressed that these unemployed doctors would come to Britain in search of further training. The available statistics however, do not support this xenophobia, as there has been less than $1 \%$ internal migration of doctors in the EEC. Furthermore, a recent survey of medical manpower in the EEC by the Permanent Working Group of European Junior Doctors has indicated that although the current overproduction of doctors will remain until about 2005 , there will thereafter be an increasing shortfall in medical manpower throughout Europe. This will be exacerbated by the increasing numbers of women entering medicine, who will increasingly demand part-time work and maternity leave.

Under current European law, any doctor who has completed his or her specialist training in his or her own country is eligible to apply for a consultant post in any member state. In practice, this means that, say, an Italian doctor who has completed four years of training in Italy cannot be excluded from consideration for a consultant post in psychiatry on the basis that he/she does not fulfil UK training criteria. There now exists an animal called the European Specialist, and anybody with the minimum training of four years in psychiatry (of which one was an SR) can apply to the General Medical Council for this designation and have this recognised throughout the EEC. This should not be confused with the "T" (indicating "trained") which the GMC will place behind the names of all those of consultant status or those who have completed four years of an SR training post.

Currently the European Commission has laid down minimum standards in terms of length of time in higher specialist training, but has not as yet specified content of training. The ACMT (Advisory Committee on Medical Training) of the European Commission has issued a number of recommendations, one of which is that the European Union of Monospecialists (UEMS) should form specialist boards, whose task is to specify conditions required for training of specialists in Europe, advise the ACMT, and issue a certificate of higher specialist training. Training conditions should include the curriculum, the criteria for training centres, a system of peer control between countries, exchanges between EEC countries, and the establishment of a European Board Qualification. This may call into question the role of national exams, such as the MRCPsych.

Training in Europe is not just made difficult thanks to bureaucratic politicking. Cultural difficulties are legion. Dr van Os showed how very differently French and British psychiatrists view even such a core area as schizophrenia. British psychiatrists see schizophrenia as a predominantly biological illness, whereas "absence of the paternal image" was seen as aetiologically important by many French psychiatrists. Cognitive therapy is widely practised in the UK, especially for depression, but only rarely in France, where analytical psychotherapy is a mainstay of clinical practice.

Thus, even though legal barriers to the practice of psychiatry abroad may be coming down, cultural ones are not so easily surmounted.

\section{References}

Brearley, S. (1991) Medical manpower. British Medical Journal, 303, 1534-1536. 